\title{
Editorial: Antarctic Biology: Scale Matters
}

\author{
Bruno Danis ${ }^{1 * t}$, Anton Van de Putte ${ }^{2,3 \dagger}$, Peter Convey ${ }^{4}$, Huw Griffiths ${ }^{4}$, Katrin Linse ${ }^{4}$ and \\ Alison E. Murray ${ }^{5}$ \\ ${ }^{1}$ Marine Biology Laboratory, Université Libre de Bruxelles, Brussels, Belgium, ${ }^{2}$ OD Nature, Royal Belgian Institute of Natural \\ Sciences, Brussels, Belgium, ${ }^{3} \mathrm{KU}$ Leuven, Leuven, Belgium, ${ }^{4}$ British Antarctic Survey, Cambridge, United Kingdom, \\ ${ }^{5}$ Division of Earth and Ecosystem Sciences, Desert Research Institute, Reno, NV, United States
}

Keywords: biodiversity, Antarctica, global change, eco-evo, spatial scale, temporal scale

\section{Editorial on the Research Topic}

Antarctic Biology: Scale Matters

\section{ANTARCTICA: A TIPPING SANCTUARY}

OPEN ACCESS

Edited by:

Charles K. Lee,

University of Waikato, New Zealand

Reviewed by:

Hong Kum Lee,

Korea Polar Research Institute,

South Korea

*Correspondence:

Bruno Danis

bdanis@ulb.ac.be

†These authors have contributed equally to this work

Specialty section

This article was submitted to Biogeography and Macroecology, a section of the journal

Frontiers in Ecology and Evolution

Received: 24 January 2020

Accepted: 19 March 2020

Published: 21 April 2020

Citation:

Danis B, Van de Putte A, Convey P,

Griffiths $H$, Linse $K$ and Murray $A E$ (2020) Editorial: Antarctic Biology: Scale Matters. Front. Ecol. Evol. 8:91.

doi: 10.3389/fevo.2020.00091
A founding principle of the Antarctic Treaty is that, in the interests of all humankind, Antarctica should continue to be used exclusively for peaceful purposes and should not become the scene or object of international discord. From many standpoints, Antarctica is considered as a sanctuary, and plays a pivotal role in the global system. From an ecological point of view, Antarctica and the surrounding Southern Ocean harbor exceptional levels of biodiversity. Its ecosystems are, however, facing rapid climatic and environmental changes, and the scientific community, embodied by the Scientific Committee on Antarctic Research (SCAR), have identified the urgent need to understand the potential responses of these ecosystems. Such questions are extremely complex, as biodiversity, here defined as "the variability among living organisms from all sources, including inter alia, terrestrial, marine and other aquatic ecosystems and the ecological complexes of which they are part; this includes diversity within species, between species and of ecosystems" (Convention on Biological Diversity, 1992), can vary at many different spatio-temporal scales and levels of biological organization, from molecules to entire ecosystems.

Knowledge gaps (both Linnaean and Wallacean), previously identified by the Census of Antarctic Marine Life (2005-2010) (Schiaparelli et al., 2013), hamper our understanding and are being filled at a slow pace. This is due to both logistic and financial constraints tied to field work in the southern polar regions, and a continued reluctance from the research community and its funders toward considering raw data publication as a high priority and a means to justify their efforts.

This Research Topic offered the 137 participating authors the opportunity to publish research presented during the SCAR 12th Biology Symposium held in Leuven, Belgium, in July 2017. The main theme of the Symposium was "Scale matters." The rationale of the Symposium can be summarized as: Biological processes and diversity span all levels, from the small molecular scale, through population and up to large ecosystem scale; understanding these processes, as well as past and present patterns of biodiversity, are essential for understanding possible threats to Antarctic biology and their impacts. This collection focuses on understanding biological distribution and trends, as well as adaptation and processes, both in marine and terrestrial realms, and including human biology. Special attention is paid to multidisciplinary research and how combining insights from different fields can help understand this unique region. 
We highlight here some of the outcomes of the 20 papers assembled in this special issue, organized into three sections, focusing on our current understanding, recent developments, and future challenges that should be addressed by the Antarctic biological research community.

\section{CURRENT UNDERSTANDING OF ANTARCTIC BIODIVERSITY}

Our current knowledge of Antarctic biodiversity is derived from a mosaic of information sources, including historic data, literature, museum collections, researchers' computers and notebooks, and accessible dedicated information systems. Heindler et al. focus on museum collections, in an attempt to delineate prey and microbiome composition in fish using metabarcoding techniques. Looking back in time (between 20 and 100 years), the authors were able to obtain data and detect significant shifts in microbiome composition of trematomid fish guts, suggesting a new way to utilize museum collections to gain insight into microevolutionary processes and changes in trophic networks. Biersma et al. focused on the evolutionary history (timescale of Myr) of Antarctic flora in the terrestrial realm and proposed the existence of regional glacial refugia in the mountainous area of the Antarctic Peninsula, exploring the adaptive potential of a group of endemic species facing rapid climate change. In the marine domain, on the Antarctic continental shelf, Santagata et al. analyzed species composition in communities of bryozoans that are exposed to environmental pressures, such as ocean acidification and warming, proposing that their assemblages, which play a pivotal role as ecosystem engineers, were tied to the combined effects of seasonal ice scour and carbonate chemistry. At the microbial level, Lee et al. studied ecosystem responses to moisture gradients in the very specific environmental context of the McMurdo Dry Valleys. Here, along intense moisture gradients, the response in terms of community diversity emerged as a switch between a system driven by abiotic factors to one more sensitive to biotic factors, advancing our understanding of potential ecosystem responses in threatened systems, such as polar deserts. Also in the McMurdo Dry Valleys, Sommers et al. focused on microbial communities, but in the specialized habitat of cryoconite holes (sediment-filled melt holes on glacier surfaces), hypothesizing that higher partitioning between sediments and water would be a biodiversity driver through spatial niche partitioning; contrary to expectation, they observed the opposite, highlighting the need for further studies at even finer scales. Rego et al. presented a more methodological approach, aiming at improving the potential for High Throughput Sequencing to access the diversity of Actinobacteria and Cyanobacteria in microenvironments from the McMurdo Dry Valleys, and highlighted the importance of combining cultivation and sequencing approaches to recover both the abundant and rare components of the bacterial assemblages present. In an area displaying exceptional environmental gradients, Deception Island, Bendia et al. studied how microbial ecosystems responded to temperature, salinity, and geochemistry gradients in a volcanic setting, finding that bacterial community structure was significantly driven by all these factors, while archaeal community structure only responded to temperature variations.

Evidently, even though our knowledge of Antarctic biodiversity has greatly improved over the last decade, the Antarctic research community is constantly uncovering new realms and challenges to address, particularly in the current context of rapid environmental change.

\section{THE IMPORTANCE OF SCALES: RECENT DEVELOPMENTS}

Significant progress is being made from methodological and fundamental standpoints. In marine, freshwater and terrestrial environments, new habitats are being discovered and new approaches are being collaboratively developed to funnel new data into areas of priority research.

Once again, in the McMurdo Dry Valleys, Zaikova et al. worked on microbial mats from relict lake deposits, another under-studied, challenging oligotrophic environment. Using metagenome assemblies, they were able to attribute key roles, including nitrogen cycling and carbohydrate degradation, as well as stress responses, DNA repair and sporulation pathways, gaining new insights into functional paleoecology. Knowledge gaps not only characterize challenging environments, but also challenge understanding of taxonomy or groups that are generally assumed to be well-documented. As shown by Christiansen et al. and Christiansen et al. in a study focusing on the diversity of mesopelagic fishes using barcoding techniques, pseudo-cryptic or unrecognized species are often found in various taxa, while colonization of the Southern Ocean has occurred repeatedly for myctophids. Using a similar phylogeographic approach, combined with particle tracking models, Brasier et al. investigated the distribution of polychaete morphospecies and found that the observed distribution was linked to oceanographic parameters at regional scale, which has important implications for environmental management strategies. Using "species archetype models," Jansen, Hill, Dunstan, Eléaume et al. analyzed the value in grouping species by functional similarity in their response to environmental change, in an attempt to compensate for the scarcity of presenceabsence data. They found that this approach may insufficiently resolve this issue, highlighting the need for caution in the use of distribution models when making statements about the distribution of biodiversity at various scales and taxonomic resolutions. Scale effects were also addressed by Feeser et al. in a study addressing soil microbial diversity and community dynamics, and the scale-dependent effects of environmental heterogeneity, in the McMurdo Dry Valleys. Their results highlight the importance of conducting such studies over large ranges of environmental gradients and across multiple spatial scales. Another functional approach was used by Cummings et al. in a study focusing on marine benthic systems from the Ross Sea and linking community composition to seafloor habitat and a series of other parameters. They showed that the most powerful approach was to include all parameters at 
all scales (and finding ways to connect them), which in the longer term produced the most robust models, with promising implications for the accuracy of predictions of change in coastal habitats.

\section{REMAINING CHALLENGES: CONNECTING THE SCALES}

As mentioned above, understanding many biodiversity patterns and their responses to complex, interlinked environmental changes requires studies at multiple temporal and/or spatial scales. Coupling ocean-surface change to responses in the seafloor community is an example of such a connection, as illustrated by Jansen, Hill, Dunstan, Cougnon et al.. These authors mapped patterns of abundance of suspension feeders in East Antarctica, modeling the ways in which they responded to the 2010 calving of the Mertz glacier. Their data confirmed a strong increase in suspension feeder abundance, providing insight into the importance of a changing icescape on seafloor habitat and fauna in polar environments. In the western Antarctic Peninsula region, marine ecosystems have also been exposed to considerable icescape changes. In this region, Jerosch et al. studied the responses of macroalgae to glacial melt in fjord ecosystems, using ensemble modeling, and produced the first iteration of a quantitative model of macroalgal production under melt conditions. On a much smaller scale, Darcy et al. used a classic biogeographic theoryIsland Biogeography - to address self-contained ecosystems in the form of cryoconite holes in Taylor Valley and, more specifically, the relationships between bacterial diversity and the size of the cryconite holes and their geographic proximity. They found strong spatial structuring, suggesting that these holes are indeed behaving as "islands" in terms of bacterial diversity. Coleine et al. shared research about another peculiar niche found in Antarctica, the cryptoendolithic niche, setting out to identify if there was any relationship between abiotic parameters and fungal community biodiversity and composition. In this case, no correlations were found, presumably due to strong environmental heterogeneity at local scales, once again highlighting the need for integrated studies at multiple-scales. When assessing biodiversity patterns, spatio-temporal scales clearly matter, as highlighted by Collins et al.'s study of Victoria Land Antarctic springtails. Through collating and expanding an important dataset on Collembola CO1 DNA ("barcode") sequences, these authors found evidence for limited dispersal opportunities and strong heterogeneity in genetic diversity between sites. As a result, in the development of conservation strategies, they stress that species-specific spatio-temporal scales should be taken into consideration. Another study with urgent implications in terms of conservation is that of Ropert-Coudert et al., who focused on breeding failures in an Adélie penguin colony, and existing scenarios of entire populations collapsing, using the specific example of sharp changes in icescapes in the D’Urville Sea.

\section{INFORMATION ECOSYSTEMS ARE NEEDED TO CONNECT THE SCALES}

Antarctic science is evolving rapidly, with developments in genomics, the digital revolution, big data, modeling, etc. now being the norm. However, data mining, probing deeper into available information and museum collections, and working in a transdisciplinary manner, across-scales, also helps the research community move ahead efficiently and respond to ongoing environmental emergencies. The publication of existing and new data still needs to be improved, 10 years after the Census of Antarctic Marine Life, as information remains scattered, incomplete and often has restricted availability, which can be problematic in the light of the dissynchrony between information needs and pace of climate change in south polar regions. A further step is the predictive use of such information for research, conservation and management purposes. This requires further development in the parameterization and modeling of complex systems at the same time as supporting the maintenance of the unique knowledge of the SCAR and Antarctic community in a series of biological disciplines, which are increasingly threatened with extinction.

These predictive applications also require a better integration of Antarctic biodiversity knowledge in global biodiversity assessments (including those focusing on biosphere integrity and rate of biodiversity -function- loss). A range of global biodiversity observation initiatives and interfaces are developing, such as IPBES (the Intergovernmental Science-Policy Platform on Biodiversity and Ecosystem Services), in which Antarctic biodiversity research outputs should be better represented, and in which SCAR community practices could pave the way in terms of international collaboration, and data valorization and sharing. This approach could refine the development of biodiversity assessments and indexes at the scale of the planet. As pointed in the SCAR Horizon Scan (see e.g., Kennicutt et al., 2014), and in a recent review on sustained Antarctic research, identified priorities for Life Science research include improving our understanding of mechanisms leading to biodiversity loss, how ecosystems respond to fast changing environmental conditions, characterizing biological adaptations, defining strategies of resilience, and constantly assessing the efficacy of ongoing and future conservation practices (Kennicutt et al., 2019).

\section{AUTHOR CONTRIBUTIONS}

All authors listed have made a substantial, direct and intellectual contribution to the work, and approved it for publication.

\section{ACKNOWLEDGMENTS}

We are grateful to the SCAR Biology Leuven Symposium participants for their efforts and good spirits during the event. We are especially grateful to the reviewers who returned their comments within the requested timeline. 


\section{REFERENCES}

Kennicutt, M. C., Bromwich, D., Liggett, D., Njåstad, B., Peck, L., Rintoul, S. R., et al. (2019). Sustained Antarctic research: a 21st century imperative. One Earth 1, 95-113. doi: 10.1016/j.oneear.2019.08.014

Kennicutt, M. C., Chown, S. L., Cassano, J. J., Liggett, D., Massom, R., Peck, L. S., et al. (2014). Polar research: six priorities for Antarctic science. Nat. News 512, 23-25. doi: 10.1038/512023a

Schiaparelli, S., Danis, B., Wadley, V., and Stoddart, D. M. (2013). “The census of Antarctic Marine Life: the first available baseline for Antarctic marine biodiversity," in Adaptation and Evolution in Marine Environments, Vol. 2 (Berlin; Heidelberg: Springer), 3-19.
Conflict of Interest: The authors declare that the research was conducted in the absence of any commercial or financial relationships that could be construed as a potential conflict of interest.

Copyright (๑) 2020 Danis, Van de Putte, Convey, Griffiths, Linse and Murray. This is an open-access article distributed under the terms of the Creative Commons Attribution License (CC BY). The use, distribution or reproduction in other forums is permitted, provided the original author(s) and the copyright owner(s) are credited and that the original publication in this journal is cited, in accordance with accepted academic practice. No use, distribution or reproduction is permitted which does not comply with these terms. 